\title{
Quality Validation of Platelets Obtained From the Haemonetics and Trima Accelautomated Blood-collection Systems
}

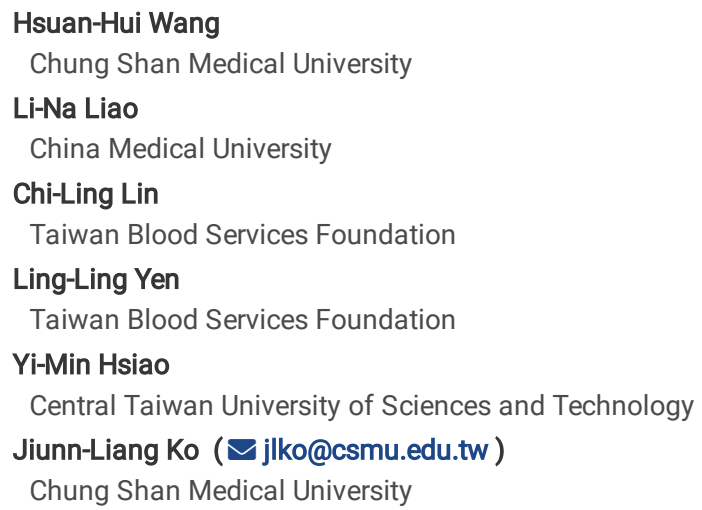

\section{Research}

Keywords: platelet apheresis (PPH), leucocyte-reduced platelets apheresis(LRPH), plateletqualities, bacterium-screening test

Posted Date: July 6th, 2020

DOI: https://doi.org/10.21203/rs.3.rs-38756/v1

License: (c) (i) This work is licensed under a Creative Commons Attribution 4.0 International License. Read Full License 


\section{Abstract}

Background: Platelet transfusion is required to treat haemo-oncology or trauma patients. Platelet apheresis (PPH) performed with apheresis equipment has increased rapidly in recent years. Leucocyte-reduced platelet apheresis (LRPH) can reduce the risk of platelet refractoriness and febrile nonhemolytic transfusion reactions (FNHTRs) for transfusion. Accordingly, this study aimed to investigate and compare the platelet metabolic and functional responses between PPH performed with Haemonetics and LRPH performed with Trima Accel cell separator.

Methods: The qualities of platelets collected through PPH and LRPH were evaluated in terms of visual appearance, morphology, platelet-aggregation changes, metabolic activities, and bacterium-screening test during 5-day storage. Statistical analyses included two-sample t-test and generalised estimating equation(GEE) method.

Results: During 5-day storage in LRPH, residual leucocytes were all $<1.0 \times 10^{6}$, and the parameters of platelet function were as follows: platelet aggregated to agonists such as adenosine $5^{\prime}$-diphosphate (ADP) and collagen, and the extent of shape change and $\mathrm{pO}_{2}$ showed no statistically significant difference between PPH and LRPH. The hypotonic shock reaction (HSR) on days 0,1 , and 3 were significantly higher in LRPH than in PPH (71.78 \pm 6.92 vs. $64.10 \pm 7.42$; $p=0.002 ; 71.53 \pm 8.98$ vs. $62.96 \pm 9.84 ; p=0.007 ; 68.05 \pm 7.28$ vs. $57.76 \pm 6.80 ; p<0.0001$, respectively). Values of mean platelet volume (MPV) were statistically larger in PPH than in LRPH on days 0,1 , and 3. On day 5, the swirling score was higher in LRPH than in PPH. The mean lactate levels had no statistically significant difference between PPH and LRPH. Moreover, no growth was observed through bacterium-screening test conducted on 40 samples.

Conclusion: Comparison of LRPH and PPH products collected from the Trima Accel and Haemonetics automated blood-collection systems, respectively, revealed that both products possessed good platelet qualities even though additional processes are needed to reduce leucocytes. Furthermore, investigating the outcomes of other apheresis instruments with focus on the safety of donors, products, and recipients is necessary.

\section{Background}

Platelets (PLTs) play a necessary role in preventing blood loss after traumatic injury and major haemorrhage. For thrombocytopenia and bleeding, transfusing PLT components (PCs) are an important treatment. A pool of four to six concentrates of whole-blood donations is a usual dose of PLT transfusion. To reduce donor exposure, transfusing single-donor apheresis components for patients is preferred. PLT transfusion plays a vital role in patients with hematooncological disorders.

The recommended storage temperature of PCs is $20-24^{\circ} \mathrm{C}$ under continuous gentle agitation. Bacterial contamination of PCs is attributed to storage conditions because the condition facilitates the proliferation of bacterial contaminants. The storage temperature permits human and environmental microflora growth. The storage time is often limited to 5 days for PCs owing to the risk of bacterial contamination [1]. Haemovigilance reports confirm that clinical transfusion incidents occur through PC bacterial contamination [2]. Minimizing the risk of bacterial transfusion transmitted infectious diseases is an important issue. The contamination of PCs by bacteria lead to the development of a pause of PLT swirling [3].

The demand for PLT apheresis (PPH) by patients has increased over the past years. Accordingly, the collection of blood components by using apheresis instruments has rapidly increased. The advantages of PPH collection include the control of component volumes and high-quality products. The use of apheresis equipment is rapidly growing to provide the optimum blood components to patients. Thus, PPH transfusion has become essential therapy in modern medicine.

The leucocytes of blood components may induce adverse events in patients during or after transfusion. The most important ones are transfusion-associated nonhaemolytic febrile transfusion reactions, graft-versus-host disease, alloimmunisation to human-leucocyte antigen, and human T-lymphotropic virus (HTLV) or CMV infections [4]. Leucocyte-reduced components may also prevent prion infections [5].

Using leucocyte-reduced blood components can decrease the incidence rate of PLT refractoriness. A study has shown that alloimmunisation rates an be significant decreased by transfused leucocyte-reduced PLT apheresis (LRPH) compared with nonleucocyte-reduced PCs [6]. To reduce side effects, almost all PCs are leucocyte reduced in Europe [7].

Another study that used four agonists for the pre-storage leukodepletion of PCs on day 5 has shown that improving the quality and PLT-aggregation activity has no advantage and may even be detrimental [8]. Technical advances have improved the productivity and quality of apheresis-PLT-collection methods, particularly those involving automated cell separators, to enable PC production without filtration.

The present study aimed to examine the effects of the Trima Accel device on leucocyte-reduced cell separation and compare the metabolic and functional responses between the PPH and LRPH products of Haemonetics and Trima Accel automated blood-collection systems.

\section{Methods}

\subsection{Study design and participants}

All of the participants in this study met the criteria for blood donors in accordance with Taiwan's Ministry of Health and Welfare guidelines and were recruited in the Taichung Blood Center, located in central Taiwan. 
The eligibility criteria for double units ( $\geq 3 \times 10^{11} \mathrm{PLTs} /$ unit) were as follows: (1) age 17-65 years; (2) preapheresis PLT count $\geq 300 \times 10^{3} / \mu \mathrm{L}$ and $\geq 250 \times$ $10^{3} / \mu \mathrm{L}$ for Haemonetics MCS + ED and Trima Accel, respectively; (3) haemoglobin ( $\mathrm{Hb}$ ) level from 13.5-18.5 g/dL for male; (4) donor body weight $\geq 60 \mathrm{~kg} ;$ (5) negative tests for hepatitis B surface antigen, hepatitis C, human immunodeficiency virus, HTLV, and syphilis, and normal level of alanine aminotransferase; (6) in good health; and (7) no drugs taken in the last 7 days (those taking aspirin or anti-inflammatory drugs were not allowed to donate blood).

If donors have been fasting, we asked them to eat a meal or offered them snacks, water, drink, or milk before donation. Almost all PPH and LRPH donors in Taiwan were male. From June to September 2013, 40 eligible male donors were recruited to participate in this study.

\subsection{Data collection}

Donors were individually subjected to the blood collection with Haemonetics or Trima Accel device. Vital signs included systolic and diastolic blood pressure, and pulse was monitored and recorded at the beginning and end of the procedure. The donors were also monitored for adverse events during the procedures. The following data were entered into the cell-separator program for both devices: donor height, weight, gender, hematocrit, and pre-count of PLT values. Welltrained apheresis staff performed all the procedures. The body mass index (BMI), defined as the body mass divided by the square of body height, was also recorded.

\subsection{Instruments and quality control}

A Haemonetics MCS + ED cell separator (Braintree, MA, USA) was used with a targeted yield of $6 \times 10^{11}$ PLTs for double units. The whole-blood flow was set to $85 \mathrm{~mL} / \mathrm{min}$, which can be modified by the collection staff depending on the donors' venous condition. The acid citrate dextrose-A (ACD-A) anticoagulant (AC)/whole-blood ratio was 1:10 $(n=20)$. The second device used for PLT collection was Trima Accel software version 5.0 (Caridian BCT, Lakewood, CO, USA) with a targeted yield of $6 \times 10^{11}$ PLTs for double units. The whole-blood flow was $75-100 \mathrm{~mL} / \mathrm{min}$ the, and the ACD-A AC/whole-blood ratio was $1: 11$ ( $n=20$ ). Quality control tests for the residual leucocytes of LRPH collected with Trima Accel version 5.0 were performed by manually counting the cells in the Nageotte chamber as described elsewhere [9]. A previous study has shown that resident skin flora are the major bacterial contamination in PCs [10]. One strategy to reduce such contamination is to use a diversion bag for the first aliquot of the donation. The volume of this diversion bag is then used for routine laboratoryscreening tests, such as blood-type and infection-disease testing. The collected apheresis sets from the two instruments in this work included the diversion pouch. The quality-control criteria for the product were determined through standard operation procedure (SOP). At least $90 \%$ of units sampled contained $\geq$ $3.0 \times 10^{11} \mathrm{PLTs}$, and at least $90 \%$ of units had a pH $\geq 6.2$ during 5-day storage. Moreover, the residual leucocytes of LRPH were $<5 \times 10^{6}$ per final product for $95 \%$ of units sampled.

\subsection{Visual appearance}

When discoid PLTs are exposed to a light source, swirling is caused by the reflection of light. This swirling can be used to evaluate PLT function. Herein, swirling was assessed by visual inspection, and we defined the scores as follows: 0, no swirling; 1, limited swirling; and 2, maximum swirling.

\subsection{Laboratory testing}

Pre- and post-apheresis samples were subjected to complete blood counts (CBCs) by using an automated blood-cell counter (Sysmex KX-21N, Sysmex Corp., Kobe, Japan). PLT quality was examined through morphological, biochemical, and functional changes on days 0 , 1, 3, and 5. The PLT count and mean PLT volume (MPV) were tested. The potential marker of PLT reactivity was used to measure MPV. PLT shapes ranged from discoid to spheroid, and the MPV increased (swelling) in correlation with reduced PLT survival. Loss of swirling was associated with loss of PLT function.

PLT-aggregation changes were examined by light transmission aggregometry (Chrono-log 490-4D) in response to adenosine 5'-diphosphate (ADP) and collagen (CHRONO-LOG, Leiden, the Netherlands)-induced aggregation. For ADP-induced aggregation, the final concentration of PLT rich plasma (PRP) was $300 \times 10^{3} \mu \mathrm{L}$, and the corresponding PLT poor plasma served as the control. About $450 \mu \mathrm{L}$ of PRP was placed in a reaction cup under continuous stirring at $37^{\circ} \mathrm{C}$, and then $50 \mu \mathrm{L}$ of $\mathrm{ADP}$ (final concentration $=30 \mu \mathrm{M}$ ) was added to the PRP sample. PLT-aggregation activity was then tested. About $490 \mu \mathrm{L}$ of PRP was placed in a reaction cup under continuous stirring at $37^{\circ} \mathrm{C}$, and then $10 \mu \mathrm{L}$ of collagen (final concentration, $20 \mu \mathrm{g} / \mu \mathrm{L}$ ) was added to the PRP sample. Collagen-induced aggregation activity was then tested.

Hypotonic shock response (HSR) and extent of shape change (ESC) were explored to evaluate PLT survival. $\mathrm{pO}_{2}, \mathrm{pCO}_{2}$, glucose, and lactate tests were conducted to examine PLT storage.

HSR was measured according to dynamic light transmittance through light transmission aggregometry and calculated as follows: $\mathrm{HSR}=[(\mathrm{Y}-\mathrm{a}) /(\mathrm{Y}-\mathrm{X})] \times$ $100 \%$, where $X$ is the transmittance of normal-saline-diluted PRP, $Y$ is the maximum transmittance of deionized-water-diluted PRP, and "a" is the minimum transmittance of deionized-water-diluted PRP.

PLT shape change, as one of the earliest morphological indicators of PLT activation, was subsequently examined. ESC was tested by adding $10 \mu \mathrm{L}$ of $0.1 \mathrm{M}$ ethylenediaminetetraacetate to PRP. Subsequent aggregation was blocked by adding $10 \mu \mathrm{L}$ of $0.1 \mathrm{mM}$ ADP. The change in shape was measured by light transmission aggregometry.

The $\mathrm{pH}, \mathrm{pO}_{2}, \mathrm{pCO}_{2}$, lactate, and glucose values were measured using an automatic blood gas analyser (GEM Premier 3000 , Werfen) at $22{ }^{\circ} \mathrm{C}$.

The bacterium-screening tests for all PPH and LRPH were conducted in 2007 in Taichung Blood Center. About 8 mL of sample was collected from each PLT unit $\geq 24 \mathrm{~h}$ after blood donation and inoculated in an automated blood-culture system (BacT/ALERT®, bioMérieux, Marcy l'Etoile, France). $\mathrm{CO}_{2}$ production was monitored to determine bacterial growth, which changed the color from grey to yellow at the bottom of the culture bottle as detected with a gas- 
permeable sensor [11]. Each sample was placed in an aerobic culture bottle inoculated in the automated culture system for up to $24 \mathrm{~h}$ at $35-37^{\circ} \mathrm{C}$. APs were released to the hospital if no growth was observed.

\subsection{Statistical analysis}

Continuous variables were reported as the mean \pm standard deviation. The two-sample t-test was used for continuous variables in bivariate analysis.

To further assess PLT function on different days, i.e., to compare the results of days 0 with those of day 1,3 and 5, the method of generalised estimating equations was used by considering the dependence. A p value less than 0.05 was considered as statistically significant. All analyses were performed with SAS version 9.4 (SAS Institute Inc, Cary, NC, USA).

\section{Results}

\subsection{Sample characteristics}

The demographic characteristics and $\mathrm{CBC}$ data of a total 40 male donors ( $\mathrm{N}=20$ per group) are shown in Table 1. No statistically significant difference was observed between the two groups in terms of age, weight, height, donation times, and BMI of the participants. Moreover, no significant difference in CBC values before and after blood donations was observed.

the participants

Table1.

The demographic characteristics and pre-apheresis laboratory data of the participants

\begin{tabular}{|c|c|c|c|}
\hline \multirow[t]{2}{*}{ Variable } & \multirow{2}{*}{$\begin{array}{l}\mathrm{PPH}(\mathrm{n}=20) \\
\text { mean } \pm S D\end{array}$} & \multicolumn{2}{|l|}{ LRPH $(n=20)$} \\
\hline & & mean $\pm S D$ & $\mathrm{p}$-value \\
\hline Age (years) & $41.15 \pm 7.87$ & $42.85 \pm 7.66$ & 0.493 \\
\hline Donated_times & $478.00 \pm 325.20$ & $387.90 \pm 269.20$ & 0.346 \\
\hline Weight (kg) & $78.60 \pm 10.59$ & $73.73 \pm 9.07$ & 0.126 \\
\hline Heigth (m) & $1.72 \pm 0.05$ & $1.71 \pm 0.07$ & 0.379 \\
\hline BMI $\left(\mathrm{kg} / \mathrm{m}^{2}\right)$ & $26.47 \pm 3.18$ & $25.37 \pm 2.85$ & 0.255 \\
\hline Pre-WBC (î10³/ul) & $5.96 \pm 1.30$ & $5.96 \pm 1.23$ & 1.000 \\
\hline $\mathrm{Hb}(\mathrm{g} / \mathrm{dl})$ & $14.97 \pm 0.85$ & $14.9 \pm 0.89$ & 0.787 \\
\hline Hct (\%) & $43.26 \pm 2.13$ & $43.03 \pm 2.10$ & 0.738 \\
\hline \multicolumn{4}{|c|}{ PPH=plateletapheresis ;LRPH=leukocyte-reduced platelets apheresis ; } \\
\hline \multicolumn{4}{|c|}{$\mathrm{Hb}=$ hemoglobin;Hct=hematocrit; $\mathrm{WBC}=$ white blood cell; $\mathrm{BMI}=$ body mass index } \\
\hline \multicolumn{4}{|c|}{ SD indicates standard deviation; p-value by t-test } \\
\hline
\end{tabular}

\subsection{Haemonetics and Trima Accel systems}

The universal PLT protocol (UPP) disposable set elements were efficiently installed as follows: 1, PLT storage bags and air removal/sample pouch; 2 , airmanagement bag; 3, plasma bag; 4, centrifuge bowl and dual pump manifold; 5, anti-coagulant (AC), saline line, and donor lines; and 6, blood filter chamber. The bowl was centrifuged well, and the head of the bowl was firmly pressed down on to fully seat it in the centrifuge chuck. The dual pump tubing around the "Blood" and "Transfer "pumps was looped in preparation for the pump autoload sequence. The single pump manifold was snapped into place, and the AC tubing was looped around the AC pump.

The system collected the PLT layer in a small volume of plasma to obtain concentrated PLT products. If the PLT yield was $6 \times 10^{11}$ or above, Haemonetics recommends opening the clamps on both PLT storage bags. The MCS + UPP disposable set is shown in Fig. 1.

To separate whole blood into PCs by using Trima Accel system, a continuous-flow centrifuge was used. Whole blood was collected from the blood donor and mixed with an AC. The mixture was pumped into the channel that was a plastic pathway set in the centrifuge filter with a well-designed groove. Five pumps drew and returned the blood from the donor by using the Trima Accel system. A cassette that was part of the tubing set guided the flow of blood and products.

A leucoreduction system (LRS) was used in Trima Accel to minimize the leucocyte content of LRPH products. Following the principle of elutriation, the chamber enabled the separation of PLTs from leucocytes through the technology of saturated, fluidized particle-bed filtration. The LRS chamber trapped the 
leucocytes, which can solve the problem of low-yield PLT collection for LRPH. The tubing set, cassette overview, and LRS are shown in Fig. 2. The system can consistently collect LRPH products with residual leucocytes $<1.0 \times 10^{6}$.

\subsection{PLT qualities}

The results of comparing PLT qualities between PPH (MCS+) and LRPH (Trima Accel) products during storage days 0, 1, 3, and 5 are presented in Table 2. The MPV values were statistically larger in PPH than in LRPH on days 0,1 , and 3. PPH and LRPH units were scored as good swirling on days 0 , 1 , and 3 . On day 5 , the swirling score was better in LRPH than in PPH. The ability of PLT to aggregate to ADP and collagen showed no statistically significant difference between PPH and LRPH during days $0,1,3$ and 5 . HSR on days 0,1 and 3 were significantly higher in LRPH than in PPH $(71.78 \pm 6.92$ vs. $64.10 \pm 7.42 ; \mathrm{p}=0.002 ; 71.53$ \pm 8.98 vs. $62.96 \pm 9.84 ; p=0.007$; and $68.05 \pm 7.28$ vs. $57.76 \pm 6.80 ; p<0.0001$, respectively). ESC showed no statistically significant difference between the two groups. The $\mathrm{pH}$ of LRPH products was significantly higher than that of $\mathrm{PPH}$ products on days 0,1 , and $3(7.21 \pm 0.03 \mathrm{vs}$. $7.17 \pm 0.03 ; \mathrm{p}<0.001 ; 7.29 \pm 0.04$ vs. $7.26 \pm 0.03 ; p=0.015$; and $7.30 \pm 0.05$ vs. $7.27 \pm 0.04 ; p=0.041$, respectively). For $\mathrm{pO}_{2}$, no statistically significant difference was found between $\mathrm{PPH}$ and $\mathrm{LRPH}$ products during days $0,1,3$, and $5 . \mathrm{pCO}_{2}$ was significantly higher in $\mathrm{LRPH}$ than in $\mathrm{PPH}$ on days 3 and $5(31.20 \pm 2.35 \mathrm{vs}$. $29.25 \pm 1.92 ; \mathrm{p}=0.007$; and $28.45 \pm 1.79$ vs. $26.55 \pm 2.06 ; p=0.004$, respectively). The mean glucose levels were higher in PPH than in LRPH on days 0,1 , and 3 ( $361.90 \pm 23.34$ vs. $342.90 \pm 27.16 ; p=0.023 ; 354.40 \pm 19.71$ vs. $334.40 \pm 26.32 p=0.010$; and $322.70 \pm 22.26$ vs. $301.20 \pm 25.12 ; p=0.007$, respectively). The mean lactate levels had no statistically significant difference between PPH and LRPH products during days $0,1,3$, and 5 . The residual leucocytes of LRPH were statistically significant lower than PPH during 5-day storage.

Table 2

Comparing the platelet qualities between PPH (MCS+) and LRPH (Trima) on day 0, 1, 3, and 5

\begin{tabular}{|c|c|c|c|c|c|c|c|c|c|c|c|c|}
\hline \multirow[t]{2}{*}{ Variables } & \multicolumn{3}{|l|}{ Day 0} & \multicolumn{3}{|l|}{ Day 1} & \multicolumn{3}{|l|}{ Day 3} & \multicolumn{3}{|l|}{ Day 5} \\
\hline & PPH & LRPH & p-value & PPH & LRPH & $\begin{array}{l}\mathrm{p}- \\
\text { value }\end{array}$ & PPH & LRPH & $\begin{array}{l}\text { p- } \\
\text { value }\end{array}$ & PPH & LRPH & $\begin{array}{l}\mathrm{p}- \\
\text { value }\end{array}$ \\
\hline MPV (fl) & $\begin{array}{l}7.99 \pm \\
0.49\end{array}$ & $\begin{array}{l}7.68 \pm \\
0.47\end{array}$ & 0.047 & $\begin{array}{l}7.83 \pm \\
0.45^{*}\end{array}$ & $\begin{array}{l}7.51 \pm \\
0.43^{\#}\end{array}$ & 0.030 & $\begin{array}{l}7.80 \pm \\
0.47^{*}\end{array}$ & $\begin{array}{l}7.47 \pm \\
0.43^{\#}\end{array}$ & 0.028 & $\begin{array}{l}7.81 \pm \\
0.44^{*}\end{array}$ & $\begin{array}{l}7.53 \pm \\
0.46^{\#}\end{array}$ & 0.057 \\
\hline Swirling score & $\begin{array}{l}2.00 \pm \\
0.00\end{array}$ & $\begin{array}{l}2.00 \pm \\
0.00\end{array}$ & - & $\begin{array}{l}2.00 \pm \\
0.00\end{array}$ & $\begin{array}{l}2.00 \pm \\
0.00\end{array}$ & - & $\begin{array}{l}1.95 \pm \\
0.22\end{array}$ & $\begin{array}{l}2.00 \pm \\
0.00\end{array}$ & 0.330 & $\begin{array}{l}1.50 \pm \\
0.51^{*}\end{array}$ & $\begin{array}{l}1.80 \pm \\
0.41^{\#}\end{array}$ & 0.048 \\
\hline $\operatorname{ADP}(\mu \mathrm{M})$ & $\begin{array}{l}86.75 \\
\pm 25.97\end{array}$ & $\begin{array}{l}86.15 \\
\pm 20.08\end{array}$ & 0.935 & $\begin{array}{l}41.98 \\
\pm \\
24.06^{*}\end{array}$ & $\begin{array}{l}39.97 \\
\pm \\
18.76^{\#}\end{array}$ & 0.771 & $\begin{array}{l}19.79 \\
\pm \\
16.10^{*}\end{array}$ & $\begin{array}{l}25.83 \\
\pm \\
15.40^{\#}\end{array}$ & 0.233 & $\begin{array}{l}13.20 \pm \\
9.45^{*}\end{array}$ & $\begin{array}{l}20.30 \\
\pm \\
14.67^{\#}\end{array}$ & 0.077 \\
\hline Collagen $(\mu \mathrm{g} / \mathrm{ml})$ & $\begin{array}{l}106.60 \\
\pm 15.29\end{array}$ & $\begin{array}{l}108.10 \\
\pm 7.63\end{array}$ & 0.713 & $\begin{array}{l}84.44 \\
\pm \\
15.80^{*}\end{array}$ & $\begin{array}{l}85.85 \\
\pm \\
12.74^{\#}\end{array}$ & 0.757 & $\begin{array}{l}73.50 \\
\pm \\
21.55^{*}\end{array}$ & $\begin{array}{l}70.23 \\
\pm \\
22.14^{\#}\end{array}$ & 0.639 & $\begin{array}{l}53.09 \pm \\
23.76^{*}\end{array}$ & $\begin{array}{l}51.01 \\
\pm \\
22.24^{\#}\end{array}$ & 0.776 \\
\hline HSR (\%) & $\begin{array}{l}64.10 \\
\pm 7.42\end{array}$ & $\begin{array}{l}71.78 \\
\pm 6.92\end{array}$ & 0.002 & $\begin{array}{l}62.96 \\
\pm 9.84\end{array}$ & $\begin{array}{l}71.53 \\
\pm 8.98\end{array}$ & 0.007 & $\begin{array}{l}57.76 \\
\pm 6.80^{*}\end{array}$ & $\begin{array}{l}68.05 \\
\pm 7.28\end{array}$ & $\dot{0} 001$ & $\begin{array}{l}55.67 \pm \\
8.14^{*}\end{array}$ & $\begin{array}{l}60.77 \\
\pm \\
10.50^{\#}\end{array}$ & 0.094 \\
\hline ESC (\%) & $\begin{array}{l}20.98 \\
\pm 2.50\end{array}$ & $\begin{array}{l}21.29 \\
\pm 3.37\end{array}$ & 0.745 & $\begin{array}{l}17.13 \\
\pm 2.59^{\star}\end{array}$ & $\begin{array}{l}18.57 \\
\pm 2.63^{\#}\end{array}$ & 0.088 & $\begin{array}{l}14.93 \\
\pm 3.64^{\star}\end{array}$ & $\begin{array}{l}16.77 \\
\pm 3.82^{\#}\end{array}$ & 0.128 & $\begin{array}{l}13.37 \pm \\
3.32^{\star}\end{array}$ & $\begin{array}{l}13.80 \\
\pm 4.64^{\#}\end{array}$ & 0.734 \\
\hline $\mathrm{pH}$ & $\begin{array}{l}7.17 \pm \\
0.03\end{array}$ & $\begin{array}{l}7.21 \pm \\
0.03\end{array}$ & $<0.001$ & $\begin{array}{l}7.26 \pm \\
0.03^{*}\end{array}$ & $\begin{array}{l}7.29 \pm \\
0.04^{\#}\end{array}$ & 0.015 & $\begin{array}{l}7.27 \pm \\
0.04^{*}\end{array}$ & $\begin{array}{l}7.30 \pm \\
0.05^{\#}\end{array}$ & 0.041 & $\begin{array}{l}7.21 \pm \\
0.06\end{array}$ & $\begin{array}{l}7.24 \pm \\
0.06^{\#}\end{array}$ & 0.052 \\
\hline pCO2 (mmHg) & $\begin{array}{l}50.20 \\
\pm 4.10\end{array}$ & $\begin{array}{l}49.60 \\
\pm 3.44\end{array}$ & 0.619 & $\begin{array}{l}36.65 \\
\pm 2.28^{*}\end{array}$ & $\begin{array}{l}37.85 \\
\pm 2.92^{\#}\end{array}$ & 0.156 & $\begin{array}{l}29.25 \\
\pm 1.92^{*}\end{array}$ & $\begin{array}{l}31.20 \\
\pm 2.35^{\#}\end{array}$ & 0.007 & $\begin{array}{l}26.55 \pm \\
2.06^{*}\end{array}$ & $\begin{array}{l}28.45 \\
\pm 1.79^{\#}\end{array}$ & 0.004 \\
\hline p02 (mmHg) & $\begin{array}{l}96.70 \\
\pm 12.15\end{array}$ & $\begin{array}{l}95.50 \\
\pm 11.66\end{array}$ & 0.752 & $\begin{array}{l}93.30 \\
\pm 11.78\end{array}$ & $\begin{array}{l}92.70 \\
\pm 9.85\end{array}$ & 0.862 & $\begin{array}{l}102.40 \\
\pm 11.51\end{array}$ & $\begin{array}{l}102.10 \\
\pm \\
10.23^{\#}\end{array}$ & 0.931 & $\begin{array}{l}104.00 \\
\pm 13.42^{\star}\end{array}$ & $\begin{array}{l}101.20 \\
\pm \\
11.46^{\#}\end{array}$ & 0.482 \\
\hline Glucose (mg/dl) & $\begin{array}{l}361.90 \\
\pm 23.34\end{array}$ & $\begin{array}{l}342.90 \\
\pm 27.16\end{array}$ & 0.023 & $\begin{array}{l}354.40 \\
\pm \\
19.71^{\star}\end{array}$ & $\begin{array}{l}334.40 \\
\pm \\
26.32^{\#}\end{array}$ & 0.010 & $\begin{array}{l}322.70 \\
\pm \\
22.26^{*}\end{array}$ & $\begin{array}{l}301.20 \\
\pm \\
25.12^{\#}\end{array}$ & 0.007 & $\begin{array}{l}289.80 \\
\pm 23.47^{*}\end{array}$ & $\begin{array}{l}274.40 \\
\pm \\
31.48^{\#}\end{array}$ & 0.089 \\
\hline Lactate (mM) & $\begin{array}{l}2.33 \pm \\
0.51\end{array}$ & $\begin{array}{l}2.33 \pm \\
0.50\end{array}$ & 0.975 & $\begin{array}{l}3.50 \pm \\
0.46^{*}\end{array}$ & $\begin{array}{l}3.48 \pm \\
0.54^{\#}\end{array}$ & 0.876 & $\begin{array}{l}7.00 \pm \\
0.79^{*}\end{array}$ & $\begin{array}{l}6.81 \pm \\
0.86^{\#}\end{array}$ & 0.485 & $\begin{array}{l}10.55 \pm \\
1.38^{*}\end{array}$ & $\begin{array}{l}10.03 \\
\pm 1.26^{\#}\end{array}$ & 0.221 \\
\hline $\begin{array}{l}\text { WBC residual } \\
\left.\text { ( } \in 10^{6} / \text { unit }\right)\end{array}$ & $\begin{array}{l}6.40 \pm \\
2.26\end{array}$ & $\begin{array}{l}0.12 \pm \\
0.03\end{array}$ & $<.0001$ & $\begin{array}{l}6.04 \pm \\
2.05\end{array}$ & $\begin{array}{l}0.10 \pm \\
0.03^{\#}\end{array}$ & $\dot{0} 001$ & $\begin{array}{l}5.73 \pm \\
2.23^{*}\end{array}$ & $\begin{array}{l}0.09 \pm \\
0.03^{\#}\end{array}$ & $\hat{0.001}$ & $\begin{array}{l}5.65 \pm \\
2.15^{\star}\end{array}$ & $\begin{array}{l}0.10 \pm \\
0.03^{\#}\end{array}$ & $\dot{0.001}$ \\
\hline
\end{tabular}

MPV = mean PLT volume; $\mathrm{ADP}=$ adenosine 5'-diphosphate $; \mathrm{HSR}=$ hypotonic shock response; $\mathrm{ESC}=$ extent of shape change

p-value by t-test

*:the variable compared with day 0 for PPH, and statistically significant $(p<0.05)$ by using GEE analysis

\# the variable compared with day 0 for RLPH, and statistically significant $(p<0.05)$ by using GEE analysis 
We also compared the data of day 0 with those of days 1,3,and 5 in the PPH and LRPH groups. For PLT aggregation activity and PLT survival test, we observed that the values of ADP, collagen and ESC statistically decreased on day 1,3, and 5 compared with those on day 0 in both groups (Table 2 ). The performance of PLT storage indicated that the glucose level statistically decreased but the lactate level statistically increased compared with those on day 0 in both groups (Table 2). pH was significantly higher on days 1,3, and 5 than on day 0 in both groups (in Table 2). The residual leucocytes of LRPH significantly decreased on days 1,3 , and 5 compared with those on day 0 (Table 2).

No growth was observed through bacterium-screening tests of the 40 samples. The PPH and LRPH products met the criteria of quality control according to the SOP (data not shown). All 40 participants had no adverse events during the collection processes.

\section{Discussion}

\subsection{Main findings}

This study aimed to compare the metabolic and functional responses between the PPH and LRPH products of the Haemonetics and Trima Accel automated blood-collection systems, respectively. We assessed the quality of the products and subsequently stored condition in terms of PLT aggregation activity and PLT survival and performance during storage in PH and LRPH from different instrument in both groups during the 5-day storage. Data showed the ability of PLT to aggregate to ADP and collagen, with no difference between PPH and LRPH from different instruments during days $0,1,3$, and 5 . Moreover, the leucocyte-depletion process for LRPH collection (Trima Accel) did not affect the functional capacity and metabolic responses of the PCs. Furthermore, LRPH have better PLT survival, pH value as PLT components quality indicator and smaller MPV than PPH during days 0, 1 and 3 .

\subsection{Comparison with literature data and possible explanations}

Thrombin receptor activator for peptide 6 (TRAP-6) induces PLT aggregation. The present study showed that PCs collected from Trima Accel device responded significantly less to TRAP-6 than did MCS + PLTs [12]. This finding showed that a higher-quality PLT concentrates with least activated PLTs can be obtained by using Cobe Spectra and Trima Accel than by using MCS + and Amicus machines [13].

Our study also showed the ability of PLTs to aggregate to ADP and collagen, with no difference between PPH and LRPH form different instruments.

Various studies have evaluated PLT quality during processing and storage of different PLT pheresis instruments. The biological and morphologic changes were associated with PLT procoagulant function [14].

The present work indicated that HSR values on days 0,1 , and 3 were significantly higher in LRPH than in PPH but not on day 5 . ESC also had no statistically significant difference between the two groups during on day 5 .

The metabolic activities of $\mathrm{PPH}$ and $\mathrm{LRPH}$ were measured by the $\mathrm{pH}, \mathrm{pCO}_{2}, \mathrm{pO}_{2}$, glucose, and lactate levels. Evaluation of the $\mathrm{pCO}_{2}$ and $\mathrm{pO} \mathrm{O}_{2}$ changes in $\mathrm{PPH}$

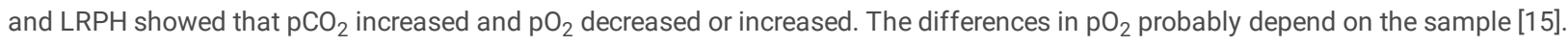

The mean pH on days 0, 1, 3 and 5 were higher than 7.0 in both PPH and LRPH from the different devices. At pH 6.0, the PLTs changed from discoid to spherical. Thus, $\mathrm{pH}$ was an indicator of stored-PLT functionality. The $\mathrm{pH}$ of PLT products must remain $\geq 6.2$ during storage under agitation at $20-24{ }^{\circ} \mathrm{C}$ according to the American Associated Blood Bank and our SOP. pH decreases because of increased lactic acid production through the glycolysis pathway. Our study showed that glucose levels decreased and lactate increased during the 5-day storage in PPH and LRPH products. Previous studies also support our data $[16,17]$.

The present research further showed that the process for LRPH collection (Trima Accel) did not affect the functional capacity of PLTs compared with PPH collection (Haemonetics MCS + ED). PLT activation decreased during storage because of WBC removal from PCs [18]

During PC storage, the biochemical, morphological, and functional changes, known as PLT storage lesion, should be detected properly and early because these are the most important aspects of PC transfusion[19] .

\subsection{Strengths And Limitations}

This study compared the metabolic and functional responses (e.g., visual appearance and bacterium-screening test responses) between the PPH and LRPH products of the Haemonetics and Trima Accel automated blood-collection systems and found that additional processe are needed to reduce leucocytes and obtain high-quality PLTs.

The transfusion of PLTs significantly increased in 2013 [20]. Since then, significant improvements have been made in terms of the efficiency and quality of PLT pheresis to offer high donor comfort. The use of apheresis PLT concentrates was intended to reduce the risk of antibody-positive TRALI [21] .

A previous study has shown that IL-1beta, IL-6, and IL-8 levels were significantly higher in post-leucocyte-reduced PPHs than in pre-leucocyte-reduced ones during storage, indicating that prestorage leukoreduction blood components reduced the transfusion-associated adverse reactions [22]. Febrile nonhaemolytic transfusion reactions (FNHTRs) are the most frequent adverse reactions for blood transfusion [23]. The risk rates of FNHTRs are higher for transfusion PLT and non-leucocyte-reduced blood products than for leucocyte-reduced ones [24, 25]. Many studies have also reported that using universal leucocyte-reduced blood components can reduce the rates of [26], which is a considerable problem for patients and hospitals [27]. Different PPH technologies can affect bacterial contamination. A higher rate of positive bacterial culture results is associated with a higher rate of apheresis PLT septic transfusion reactions [28]. The results of bacterium-screening test showed no bacterial growth using the two different devices in this work. 
Our study has several limitations. First, we did not monitor the bacterium-screening tests for PPH and LRPH to expired days (5-days). The availability of PCs was delayed for up to $48 \mathrm{~h}$ after blood collection for bacteria testing. We followed the SOP to incubate $24 \mathrm{~h}$ (only to day 2 ) by using routine test conditions for PPH and LRPH distribution to the hospital. Second limitation was the relatively small number of analyzed PPH and LRPH samples. Third limitation was that based on the criteria for donating PPH and LRPH products, the mean BMl of our participants was $>24 \mathrm{~kg} / \mathrm{m}^{2}$. BMl $>24 \mathrm{~kg} / \mathrm{m}^{2}$ is defined as overweight according to the Health Promotion Administration of the Ministry of Health and Welfare of Taiwan. The mean age of our participants was $\geq 40$ years old (middle-age was defined as 40-65 years). We also cannot analyze the association of PLT activity with different subgroups of BMI and age, respectively.

The hameovigilance system is very important for public health practitioners to understand the adverse reactions of transfusion and prevent bacterial contamination in PLTs [29]. Bacterial transmission remains a major challenge in PLT transfusion. A previous study has shown that additive solution substitutes for plasma in PLTs at $4{ }^{\circ} \mathrm{C}$ storage are necessary [30].

\section{Conclusions}

Our findings showed that LRPH collected form the Trima Accel automated blood-collection system required additional processes to reduce leucocyte and had no disadvantageous for PLT qualities compared with PPH products collected form Haemonetics device. The MPV and swirling score were better in LRPH than in PPH collected by Haemonetics machine. All products met the criteria of quality control, and no bacterial growth was observed through bacterium-screening tests.

Patients with clinical indications such as dyserythropoiesis, chemotherapy, thalassemia, bone-marrow transplantation, organ transplantation, and immunodeficiency, as well as those who had experienced two times of fever or chills and adverse reactions caused by leucocytes, should be transfused with LRPH products according to the National Health Insurance regulations in Taiwan. Further study should be conducted to investigate additional methods for reducing the adverse events caused by leucocytes and to compare the outcomes of more apheresis instruments with consideration of the safety of donors, products and recipients.

\section{Abbreviations}

PPH:Platelet apheresis; LRPH: Leukocyte-reduced platelets apheresis;

Hb: Hemoglobin; Hct: Hematocrit; WBC:White blood cell; BMI:Body mass index; FNHTRs:Febrile nonhemolytic transfusion reactions; MPV: Mean PLT volume; ADP: Adenosine 5'-diphosphate; HSR: Hypotonic shock response; ESC: Extent of shape change; GEE: Generalised estimating equation;HTLV : Human Tlymphotropic virus;ACD-A:Acid citrate dextrose-A;AC:Anti-coagulant ;PRP: PLT rich plasma;LRS: Leucoreduction system; TRAP-6: Thrombin receptor activator for peptide 6

\section{Declarations}

\section{Acknowledgement}

We thank all participants who donated blood for this study. We are also grateful to the blood-collection staff and toMr. Kuo-Chou Chen for the data gathering

\section{Authors' contributions}

Hsuan-Hui Wang wrote a first draft of this paper and performed the analysis with Li-Na Liao. Chi-Ling Lin provided medical information andLing-Ling Yencollected the data. Jiunn-Liang Ko and Yi-Min Hsiaoreviewed and editing the draft.

All authors have reviewed and accepted the final version of the manuscript.

\section{Funding}

This research was supported by the Taiwan Blood Services Foundation (PM-102-TC-118).

\section{Availability of data and material}

Taichung Blood Center of Taiwan Blood Services Foundationmanaged the data collection.

\section{Ethics approval and consent to participate}

The participants were provided with information on this study, and all signed an informed consent form. Ethical approval was obtained from the Ethical Review Board of the Taiwan BloodServices Foundation (PM-102-TC-118).

\section{Consent for publication}

Not applicable.

\section{Competing interests}

The authors declare that they have no competing interests. 


\section{References}

1. Lannan KL, et al. Resveratrol preserves the function of human platelets stored for transfusion. Br J Haematol. 2016;172(5):794-806.

2. Benjamin RJ, et al. Hemovigilance monitoring of platelet septic reactions with effective bacterial protection systems. Transfusion. 2017;57(12):2946-57.

3. Wagner SJ, Robinette D. Evaluation of swirling, $\mathrm{pH}$, and glucose tests for the detection of bacterial contamination in platelet concentrates. Transfusion. 1996;36(11-12):989-93.

4. Vamvakas EC, Blajchman MA. Universal WBC reduction: the case for and against. Transfusion. 2001;41(5):691-712.

5. Vamvakas EC. Universal white blood cell reduction in Europe: has transmission of variant Creutzfeldt-Jakob disease been prevented? Transfus Med Rev. 2011;25(2):133-44.

6. Trial to Reduce Alloimmunization to Platelets Study. G., Leukocyte reduction and ultraviolet B irradiation of platelets to prevent alloimmunization and refractoriness to platelet transfusions. N Engl J Med. 1997;337(26):1861-9.

7. Heddle NM, et al. A randomized controlled trial comparing plasma removal with white cell reduction to prevent reactions to platelets. Transfusion. 1999;39(3):231-8.

8. Weisbach V, et al. Leukocyte depletion and storage of single-donor platelet concentrates. Vox Sang. 1997;72(1):20-5.

9. Lutz P, Dzik WH. Large-volume hemocytometer chamber for accurate counting of white cells (WBCs) in WBC-reduced platelets: validation and application for quality control of WBC-reduced platelets prepared by apheresis and filtration. Transfusion. 1993;33(5):409-12.

10. de Korte D, Marcelis JH, Soeterboek AM. Determination of the degree of bacterial contamination of whole-blood collections using an automated microbedetection system. Transfusion. 2001;41(6):815-8.

11. Schmidt M, Sireis W, Seifried E. Implementation of Bacterial Detection Methods into Blood Donor Screening - Overview of Different Technologies. Transfus Med Hemother. 2011;38(4):259-65.

12. Jilma-Stohlawetz $P$, et al. In vitro platelet function of platelet concentrates prepared using three different apheresis devices determined by impedance and optical aggregometry. Transfusion. 2009;49(8):1564-8.

13. Hamid A, et al. The study of platelet activation in platelet concentrates prepared by four types of apheresis machines. Biohealth Science Bulletin. 2010;2(1):1-4.

14. Jackson SP, Schoenwaelder SM. Procoagulant platelets: are they necrotic? Blood. 2010;116(12):2011-8.

15. Jang C-S, et al. Plateletpheresis: the Process, Devices, and Indicators of Product Quality. Journal of Life Science. 2014;24(9):1030-8.

16. Diab YA, et al. Acquired cytochrome $\mathrm{C}$ oxidase impairment in apheresis platelets during storage: a possible mechanism for depletion of metabolic adenosine triphosphate. Transfusion. 2012;52(5):1024-30.

17. Johnson L, et al. Evaluation of the automated collection and extended storage of apheresis platelets in additive solution. Transfusion. 2012;52(3):503-9.

18. Vucic M, et al. Evaluation of platelet activation in leukocyte-depleted platelet concentrates during storage. Bosn J Basic Med Sci. 2018;18(1):29-34.

19. Slichter SJ, et al. Exploratory studies of extended storage of apheresis platelets in a platelet additive solution (PAS). Blood. 2014;123(2):271-80.

20. Whitaker B, et al. Trends in United States blood collection and transfusion: results from the 2013 AABB Blood Collection, Utilization, and Patient Blood Management Survey. Transfusion. 2016;56(9):2173-83.

21. Andreu G, et al. Analysis of Transfusion-Related Acute Lung Injury and Possible Transfusion-Related Acute Lung Injury Reported to the French Hemovigilance Network From 2007 to 2013. Transfus Med Rev. 2018;32(1):16-27.

22. Chang CC, et al. Transfusion-associated adverse reactions (TAARs) and cytokine accumulations in the stored blood components: the impact of prestorage versus poststorage leukoreduction. Oncotarget. 2018;9(4):4385-94.

23. Callum JL, et al., Bloody Easy 4: Blood Transfusions, Blood Alternatives and Transfusion Reactions: a Guide to Transfusion Medicine. 2016: ORBCoN, Ontario Regional Blood Coordinating Network.

24. Geiger TL, Howard SC. Acetaminophen and diphenhydramine premedication for allergic and febrile nonhemolytic transfusion reactions: good prophylaxis or bad practice? Transfus Med Rev. 2007;21(1):1-12.

25. Uhlmann EJ, et al. Prestorage universal WBC reduction of RBC units does not affect the incidence of transfusion reactions. Transfusion. 2001;41(8):9971000.

26. Martí-Carvajal AJ, et al. Pharmacological interventions for the prevention of allergic and febrile non-haemolytic transfusion reactions. Cochrane Database Syst Rev. 2010;2010(6):CD007539-9.

27. Cohen $\mathrm{R}$, et al. Feeling the burn: the significant burden of febrile nonhemolytic transfusion reactions. Transfusion. 2017;57(7):1674-83.

28. Eder AF, et al. Apheresis technology correlates with bacterial contamination of platelets and reported septic transfusion reactions. Transfusion. 2017;57(12):2969-76.

29. Jones SA, et al. Sepsis Attributed to Bacterial Contamination of Platelets Associated with a Potential Common Source - Multiple States, 2018. MMWR Morb Mortal Wkly Rep. 2019;68(23):519-23.

30. Marini I, et al. Cold storage of platelets in additive solution: the impact of residual plasma in apheresis platelet concentrates. Haematologica. 2019;104(1):207-14.

\section{Figures}


1. Donor line sample pouch

2. Donor/needle line

3. Single pump manifold

4. AC solution line

5. Blood filter chamber

6. Donor pressure monitor (DPM)

7. Dual pump manifold

8. Latham bowl

9. Plasmabag

10. System pressure monitor(SPM)

11. Air bag

12. Air removal pouch

13. Platelet storage bags

14. Saline solution line

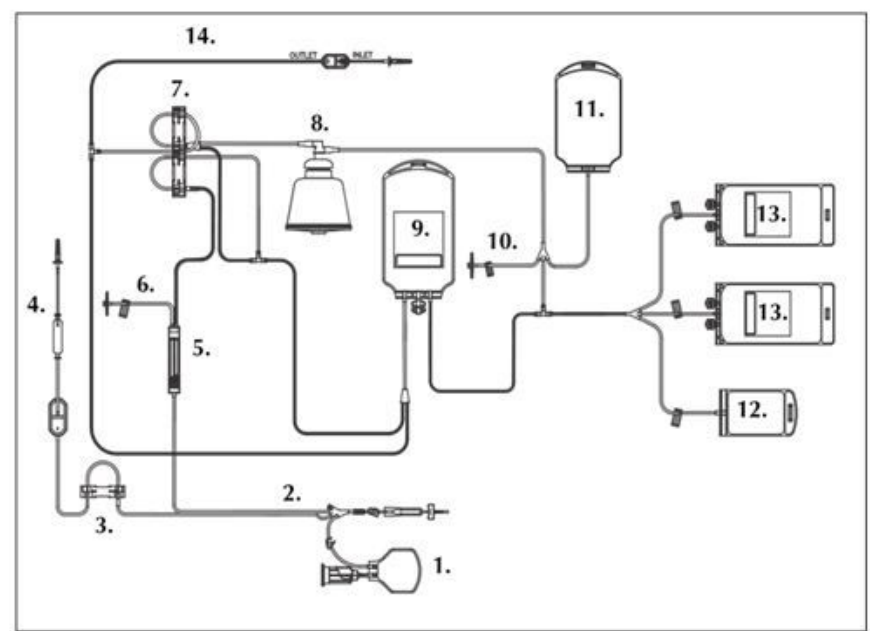

$\mathrm{AC}=$ anti-coagulant

Figure 1

Scheme of an MCS+ UPP disposable set in the Haemonetics system
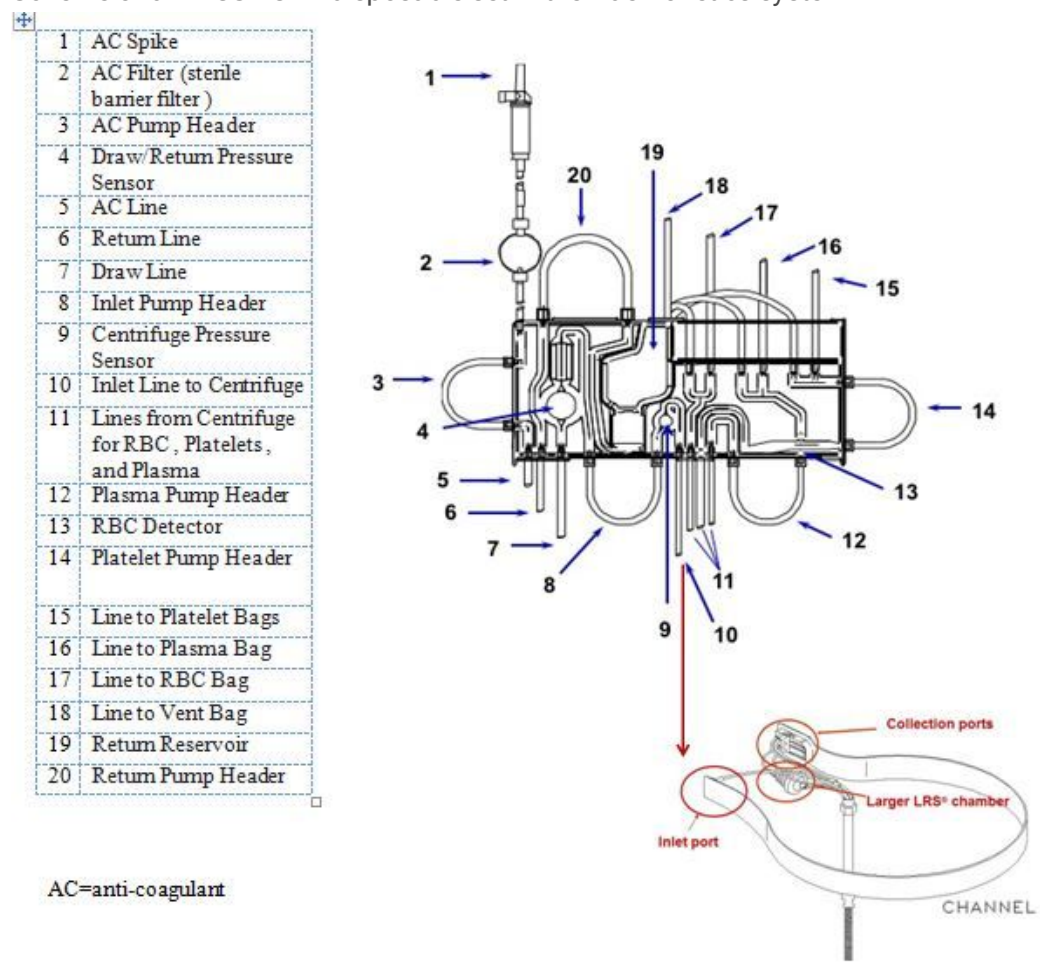

Figure 2

Scheme of tubing set, cassette overview, and LRS in the Trima Accel system 